\title{
Late-night simulation: Opinions of fourth- and fifth-year medical students at the University of the Free State, Bloemfontein,
}

\section{South Africa}

C Theron, ${ }^{1}$ medical student; T-L van Zyl, ${ }^{1}$ medical student; A Joubert, ${ }^{1}$ medical student; B Kleynhans, ${ }^{1}$ medical student;

P van der Walt, ${ }^{1}$ medical student; M G Hattingh, ${ }^{1}$ BSocSci (Nurs), BAdv (Nurs), PG Dip Labour Law, MHPE; G Joubert, ${ }^{2}$ BA, MSc

${ }^{1}$ Clinical Simulation and Skills Unit, School of Biomedical Sciences, Faculty of Health Sciences, University of the Free State, Bloemfontein, South Africa ${ }^{2}$ Department of Biostatistics, School of Biomedical Sciences, Faculty of Health Sciences, University of the Free State, Bloemfontein, South Africa

Corresponding author: $M$ Hattingh (hattinghmgm@ufs.ac.za)

\begin{abstract}
Background. Sleep deprivation is a problem for medical students and practitioners due to long and late working hours, which may result in a decline in their performance in practising medicine.

Objectives. To investigate whether educational practices require altering with regard to the time at which simulation classes are presented, or identify any other possible suggestions for improving the preparation of students for shift work in their profession as medical doctors as a potential solution to reduce sleep-deprivation-related adverse outcomes.

Methods. In this quantitative cross-sectional study, an anonymous questionnaire was distributed to 111 fourth-year and 141 fifth-year medical students at the Faculty of Health Sciences, University of the Free State (UFS), Bloemfontein, South Africa, during the second half of 2018. The researchers interpreted the responses and the Department of Biostatistics, UFS, analysed the data.

Results. The majority of the fourth-year (88.6\%) and fifth-year (90.4\%) student groups responded that late-night simulation classes between $01 \mathrm{~h} 00$ and $04 \mathrm{~h} 00$ would not be beneficial to their preparation for shift work. The motivation for negative responses was that it might worsen sleep deprivation due to time constraints in an already demanding course. The fourth-year (61.4\%) and fifth-year (80.5\%) student groups did not regard simulation as realistic and felt that late-night simulation training sessions would not prepare them better for future shift work. However, both groups believed 'practice makes perfect' and, as such, their confidence with procedures would improve as they practise more during simulation.

Conclusion. The majority of students were negative towards the idea of late-night simulation classes, because of the effect it would have on their already full programme. Students are familiar with the effects of sleep deprivation and felt that late-night simulation classes would add pressure to their busy lives and worsen their sleep deprivation. Further investigation and practical testing would be required to conclude the impact of late-night simulation classes in preparation for shift work of medical doctors and the resultant effect on clinical performance.
\end{abstract}

Afr J Health Professions Educ 2021;13(2):123-128. https://doi.org/10.7196/AJHPE.2021.v13i2.1267

Medical students and interns are prone to sleep deprivation due to long and irregular working hours. Several studies have highlighted the effects of sleep deprivation on medical doctors. ${ }^{[1-7]}$ Some medical doctors displayed a decline in their performance and mental ability due to the increase in sleep pattern disturbances and deprivation as a result of their work. ${ }^{[3]}$

The current medical internship programme in South Africa (SA) consists of a 2-year structured postgraduation period. ${ }^{[1]}$ The interns rotate in various key medical fields, such as surgical and medical disciplines, working under supervision to ensure they are competent in the clinical skills required to be an independent medical practitioner. ${ }^{[1]}$ Many of the interns currently working in SA healthcare facilities feel that they are ill-equipped for the responsibility and the workload experienced during their internship. ${ }^{[8]}$

A study conducted on the internship programme in Australia found that interns suffer from higher levels of anxiety and depression than the general population. ${ }^{[9]}$ Factors influencing increased levels of anxiety and depression include long working hours, conflict with colleagues and a stressful work environment. ${ }^{[9]}$ In the SA healthcare system, it is common practice that medical interns work shifts of $\geq 30$ hours, which have the potential to negatively affect not only the interns' abilities but also how they interact with their environment. ${ }^{[8]}$ A single night's sleep deprivation may lead to a significant decrease in a doctor's ability to complete complex tasks and reduce their problem-solving skills. ${ }^{[10]}$ Along with the decline in performance, it was also noted that other issues, such as reduced vigilance, patient aversion, loss of empathy, over-optimistic risk-taking, prolonged post-call recovery and adverse events in the medical field, were triggered by the effects of sleep deprivation resulting from long shifts. ${ }^{[10-12]}$

Medical students need to be prepared for the requirements of their profession and long working hours to maintain their cognitive abilities and decision-making to the fullest. ${ }^{[13,14]}$ The performance of students improves when they are confident about their abilities, anxiety is reduced, and they can think more clearly when posed with a problematic situation. ${ }^{[15]}$

The Clinical Simulation and Skills Unit at the Faculty of Health Sciences (FoHS), University of the Free State (UFS), Bloemfontein, SA, allows lecturers at the FoHS to train medical students on technical and nontechnical aspects required by their profession (personal communication, Prof. MJ Labuschagne, Clinical Simulation Unit, School of Clinical Medicine, 
UFS, 11 April 2018). Simulation-based training can be used by students to practise different procedures and techniques until they feel comfortable and competent. ${ }^{[15]}$ This training improves their self-confidence and makes them better doctors. ${ }^{[15]}$

A study by Laack et al., ${ }^{[16]}$ at an Australian medical school, regarding the use of extended immersive live-action simulation training, which included 'on-call' night shifts as part of the exercise, was regarded as 'highly effective' by the respondents. In a randomised, controlled trial aimed to determine the educational benefits of extended immersive simulation, it was shown that immersive simulation led to an increase in the preparedness of medical students for their role as medical doctors. ${ }^{[17]}$

\section{Definition of key terms}

The researcher's definition of late-night classes was a class between 01 h00 and $04 \mathrm{~h} 00$. This definition was used, as it was found that after $18-20$ hours without sleep, a person's ability to complete tasks is similar to that of a person suffering from minor alcohol intoxication. ${ }^{[18]}$

Total sleep deprivation can be defined as the duration of time that has passed since the end of the preceding period of sleep. ${ }^{[4]}$ Total sleep deprivation is referred to as 'sleep deprivation' throughout this study.

\section{Aim}

This study aimed to determine whether the students deemed late-night simulation-based training as beneficial in preparing them for the clinical phase of their training and their future work as interns and doctors.

The study included the following objectives:

- to determine the general sleeping patterns and sleep requirements of fourth- and fifth-year medical students at the FoHS, UFS

- to determine the effect that sleep deprivation has on the medical students

- to establish whether the medical students feel they are adequately prepared for the long working hours and late-night shifts, and the measures that could be implemented to make them feel better prepared for the demands of the work environment

- to determine the influence of clinical simulation classes on the medical students regarding the skills that they acquire, their opinions about being adequately prepared for the workload and long hours, as well as a possible reduction in errors and self-confidence while tired

- to establish whether the medical students regard late-night simulation training sessions to possibly be beneficial in preparing them for the long working hours and late-night shifts

- to describe any differences between the opinions of male v. female students

- to determine how many students have repeated a year in the MB ChB undergraduate medical programme at UFS and whether there is a link to other aspects being researched.

\section{Methods}

This was a quantitative cross-sectional study.

\section{Study population}

The target population comprised $\mathrm{MB} \mathrm{ChB}$ undergraduate medical students at the FoHS, UFS, who were in their fourth and fifth year of studies in 2018; in total 111 and 141 students, respectively. All students were eligible for participation, but those who chose not to participate and any absentees on the day that the questionnaires were distributed, were excluded.

\section{Data management}

Data were collected via an anonymous, self-administered English questionnaire distributed to all willing respondents in the study population. The researchers were present while the respondents completed the questionnaire to assist with the administration surrounding the completion and intake of questionnaires.

The researchers composed the questionnaire, which comprised closedended quantitative questions, with a number of open-ended followup questions to capture the students' opinions. ${ }^{[19]}$ Data collection was completed during the compulsory scheduled class time, which minimised logistical complications and ensured an adequate response rate.

\section{Pilot study}

The newly developed questionnaire was pre-tested to evaluate the contentrelated validity and sequencing of the questions. This questionnaire was distributed to 2 FoHS lecturers, who were familiar with the topics of the effects of shift work and simulation training, to evaluate the validity of the questionnaire, and 2 FoHS fourth-year and 2 fifth-year medical students. Additional space was provided on the questionnaire to allow for comments or suggestions by the respondents. The feedback regarding changing of the sequence of the questions and altering the categories of 2 questions was implemented. The data collected from the 6 questionnaires were excluded from the main study.

\section{Data analysis}

The quantitative data were entered into an Excel version 16 (Microsoft Corp., USA) document by the researchers as nominal categorical variables. ${ }^{[20]}$ The answers to the open-ended follow-up questions were categorised into similar themes before forming part of the data set. The researchers did the qualitative data analysis.

The quantitative data analysis was performed by the Department of Biostatistics, UFS. Results were summarised as frequencies and percentages. The $\chi^{2}$ and Fisher exact tests were used to compare the differences between the fourth- and fifth-year group responses, as well as the male and female responses in the respective year groups.

\section{Ethical approval}

Approval for the research project was obtained from the Health Sciences Research Ethics Committee (HSREC), UFS (ref. no. UFSHSD2018/0431/3107), the dean of the FoHS, dean of Student Affairs, head of the School of Clinical Medicine and the vice-rector: Research, UFS.

The respondents were provided with a short overview of the study on an information document attached to the questionnaire. The following was explained in the information document: purpose of the study; no one would benefit from the study other than the contribution that the results of the study would make to research; time required for respondents to complete the questionnaire; how data were to be protected and stored; and how anonymity would be maintained. Respondents were also assured that participation was voluntary and that they could withdraw at any stage during the data collection process without any retribution. Consent was implied by the completion of the questionnaire. To ensure anonymity, no identifiable data were collected. 


\section{Results}

A total of 71 questionnaires was received from the fourth-year class, of which 1 questionnaire had to be omitted owing to it being largely uncompleted. The response rate for the fourth-year class was $64.8 \%(n=70 / 108)$. A total of 84 questionnaires was received from the fifth-year class, of which 1 questionnaire had to be omitted owing to untrustworthy data entries. The response rate for the fifth-year class was $60.6 \%(n=83 / 137)$.

The median age for the fourth-year students was 22 (range 20 - 27) years, while the median age for the fifth-year students was $23(21-28)$ years. Almost $60 \%$ of the fourth year students were female $(58.6 \% ; n=41)$ compared with just over half of the fifth year students $(53.0 \% ; n=44)$.

Of the fourth-year respondents, $18.8 \%(n=13)$ had to repeat a year of their studies, while $21.7 \%(n=21)$ of the fifth-year respondents had to repeat a year.

The majority of fourth-year (72.9\%) and fifth-year (66.3\%) respondents indicated that they needed $7-8$ hours' sleep to feel well rested (Table 1). Two-thirds of fourth-year (65.7\%) and fifth-year students (65.1\%) reported that they usually slept $5-7$ hours a night during the academic term. A statistically significantly higher percentage of fourth-year students (89.9\%) felt they did not have enough time for sleep, work and study compared with $72.3 \%$ of fifth-year students. Both groups felt negative about their decision-making in the clinical setting when they were sleep deprived (fourth year - 60.9\%; fifth year - 49.4\%).

The majority of students from both groups (fourth year - 79.7\%; fifth year $-86.7 \%)$ felt that their sleep deprivation might negatively affect their patient interaction (Table 2). Based on the open responses given,

\begin{tabular}{|c|c|c|c|}
\hline Variable & $\begin{array}{l}\text { Fourth-year } \\
\text { students, } n(\%)\end{array}$ & $\begin{array}{l}\text { Fifth-year } \\
\text { students, } n(\%)\end{array}$ & $p$-value \\
\hline \multicolumn{4}{|c|}{ How many hours of sleep do you need to feel well rested? } \\
\hline & $n=70$ & $n=83$ & Fisher's 0.1948 \\
\hline $1-2$ & 0 & 0 & \\
\hline $3-4$ & $2(2.9)$ & 0 & \\
\hline $5-6$ & $11(15.7)$ & $22(26.5)$ & \\
\hline $7-8$ & $51(72.9)$ & $55(66.3)$ & \\
\hline$\geq 9$ & $6(8.6)$ & $6(7.2)$ & \\
\hline \multicolumn{4}{|c|}{$\begin{array}{l}\text { How many hours do you normally sleep per night during the academic } \\
\text { term? }\end{array}$} \\
\hline & $n=70$ & $n=83$ & Fisher's 0.7848 \\
\hline $1-3$ & 0 & 0 & \\
\hline $3-5$ & $13(18.6)$ & $12(14.5)$ & \\
\hline $5-7$ & $46(65.7)$ & $54(65.1)$ & \\
\hline $7-9$ & $11(15.7)$ & $16(19.3)$ & \\
\hline$\geq 9$ & 0 & $1(1.2)$ & \\
\hline \multicolumn{4}{|c|}{ Do you feel you normally have enough time for sleep, work and study? } \\
\hline & $n=69$ & $n=83$ & $\chi^{2} 0.0067$ \\
\hline Yes & $7(10.1)$ & $23(27.7)$ & \\
\hline No & $62(89.9)$ & $60(72.3)$ & \\
\hline \multicolumn{4}{|c|}{$\begin{array}{l}\text { How is your confidence in decision-making in the clinical setting } \\
\text { impacted while sleep deprived? }\end{array}$} \\
\hline & $n=69$ & $n=83$ & $\chi^{2} 0.2602$ \\
\hline Positive & $6(8.7)$ & $6(7.2)$ & \\
\hline Negative & $42(60.9)$ & $41(49.4)$ & \\
\hline Neutral & $21(30.4)$ & $36(43.4)$ & \\
\hline
\end{tabular}

the main effects mentioned by fourth-year students were negative patient interaction, student becoming irritable and student being less patient, whereas the main effects mentioned by fifth-year students were negative patient interaction, student becoming irritable and the consultation and examination being rushed.

Students felt unprepared (fourth year - 55.1\%; fifth year - 44.6\%) for the long working hours combined with their studies, but did not feel that a change in the curriculum would prepare them for the hours and study work

Table 2. Students' opinions regarding sleep deprivation and preparedness

\begin{tabular}{llll}
\hline & Fourth-year & Fifth-year & \\
Variable & students, $n(\%)$ & students, $n(\%)$ & $p$-value \\
\hline
\end{tabular}

Do you think sleep deprivation may have a negative effect on your patient interaction?

$\begin{array}{lll} & n=69 & n=83 \\ \text { Yes } & 55(79.7) & 72(86.7) \\ \text { No } & 10(14.5) & 9(10.8) \\ \text { Unsure } & 4(5.8) & 2(2.4)\end{array}$

Do you feel adequately prepared for the long hours of work and late-night shifts, combined with the amount of study hours required in the clinical phase of your training?

$\begin{array}{llll} & n=69 & n=83 & \chi^{2} 0.4792 \\ \text { Yes } & 22(31.9) & 34(41.0) & \\ \text { No } & 38(55.1) & 37(44.6) & \\ \text { Unsure } & 9(13.0) & 12(14.5) & \end{array}$

Do you think the curriculum should be adjusted to prepare you for the long hours of work and study of the clinical phase?

$\begin{array}{llll} & n=69 & n=83 & \chi^{2} 0.6157 \\ \text { Yes } & 17(24.6) & 17(20.5) & \\ \text { No } & 44(63.8) & 59(71.1) & \\ \text { Unsure } & 8(11.6) & 7(8.4) & \end{array}$

Do you think repeating procedures during simulation training assisted you to become skilled in those procedures?

$\begin{array}{lll} & n=68 & n=83 \\ \text { Yes } & 50(73.5) & 55(66.3) \\ \text { No } & 14(20.6) & 19(22.9) \\ \text { Unsure } & 4(5.9) & 9(10.8)\end{array}$

Would more simulation training sessions prepare you better for the workload and long hours of work of the clinical phase?

$\begin{array}{llll} & n=70 & n=82 & \chi^{2} 0.0249 \\ \text { Yes } & 17(24.3) & 12(14.6) & \\ \text { No } & 43(61.4) & 66(80.5) & \\ \text { Unsure } & 10(14.3) & 4(4.9) & \end{array}$

Do you think more exposure to late-night clinical work will teach you to make fewer errors and be more confident while tired?

$\begin{array}{llll} & n=70 & n=83 & \chi^{2} 0.7615 \\ \text { Yes } & 16(22.9) & 17(20.5) & \\ \text { No } & 48(68.6) & 56(67.5) & \\ \text { Unsure } & 6(8.6) & 10(12.0) & \end{array}$

Do you think clinical simulation training sessions between $01 \mathrm{~h} 00$ and $04 \mathrm{~h} 00$ would be beneficial in preparation for night-shift work?

$\begin{array}{llll} & n=70 & n=83 & \text { Fisher's } 0.9206 \\ \text { Yes } & 3(4.3) & 4(4.8) & \\ \text { No } & 62(88.6) & 75(90.4) & \\ \text { Unsure } & 5(7.1) & 4(4.8) & \end{array}$


during their clinical phase (fourth year - 63.8\%; fifth year - 71.1\%). The main suggestion in the fifth-year group regarding how their preparedness could be improved, was course adjustment. Examples of these were: 'In the second half of third year, we very suddenly went from $1-2$ classes per day that started at $09 \mathrm{~h} 00$ to being put in hospital daily from $08 \mathrm{~h} 00$ to $13 \mathrm{~h} 00$ and classes from $14 \mathrm{~h} 00$ with after-hours work. It was a dramatic change'; and 'More sleep and more reasonable daytime schedules and some night simulation training. The fourth-year group made a wide variety of suggestions, such as: 'More study time should be allocated instead of only providing 3 days to prep for 3 rd and 4 th surgery, internal medicine ... exams'; and 'From 3rd to 4th year the amount expected from you is too much. The main reason the fourth-year group required a curriculum change was that students considered the 5-year course too short: 'Course should be 6 years'; and '... make the curriculum 6 years again to give more time to study in the clinical phase.

In both year groups, the main reason why students considered repetition of procedures in simulation helpful was that practice makes perfect, whereas the main reason for disagreeing with this statement was that simulation was not realistic.

Statistically, more fifth-year students (80.5\%) than fourth-year students $(61.4 \%)$ felt that more simulation training sessions will not prepare them better $(p=0.0249)$. The main reasons for this response in both year groups were that simulation is not realistic and the course is demanding.

Almost 70\% of students from both groups (fourth year - 68.6\%; fifth year $-67.5 \%$ ) did not feel that more exposure to late-night clinical work would result in fewer errors and more confidence, as the students are tired. In both year groups, the main reasons for this response were that it would cause or worsen sleep deprivation, and the course is demanding enough. The majority of fourth-year (88.6\%) and fifth-year (90.4\%) students did not feel that clinical simulation training between $01 \mathrm{~h} 00$ and $04 \mathrm{~h} 00$ would be beneficial in preparation for night-shift work. In both year groups, the main reasons for this response were that sleep is more important, the course is demanding enough, it would cause or worsen sleep deprivation and it is not practical.

Upon further analysis, no significant associations were found between having failed a year and responses to questions. Furthermore, per year group, no significant differences were found between genders.

\section{Discussion}

\section{Response rate}

As seen in the results, the response rate for the fourth-year class was $64.8 \%$, while the response rate for the fifth-year class was $60.6 \%$. The questionnaires were distributed during information sessions presented by the $\mathrm{MB} \mathrm{ChB}$ programme management and not during academic sessions. Despite these sessions being compulsory, students often did not attend. Therefore, the most probable reason for the low response rate could be attributed to low class attendance.

This rate, however, is comparable with previous experience. In UFS undergraduate medical student projects on fifth-year medical students, the median response rate was $68 \%$, with response rates ranging from $17 \%$ to $85 \%$. Only 2 studies in fourth-year student groups have been conducted since 2001, recording response rates of $49 \%$ and $82 \%$, respectively (personal communication, Prof. G Joubert, Department of Biostatistics, School of Biomedical Sciences, UFS, 21 January 2019).

\section{Demographics}

The gender distribution for the fourth- and fifth-year student respondents showed a slight predominance of females, which is similar to the gender distribution of the classes as a whole (fourth year - 57.4\% female; fifth year $-49.6 \%$ female). The age distribution of the study population was also within the expected range appropriate for the year of study. From this it can be deduced that the response group accurately reflects the total study population.

\section{Objectives}

Objective 1: To determine the general sleeping patterns and sleep requirements of fourth- and fifth-year medical students at the FoHS, UFS

The recommended sleep duration for young adults is between 7 and 9 hours per night. ${ }^{[21]}$ The majority of both student groups felt that they require between 7 and 8 hours of sleep per night to feel well rested. However, the amount of sleep the students usually obtained was between 5 and 7 hours. Therefore, the majority of students in the fourth- and fifth-year groups were not getting enough sleep during the academic term and might have experienced varying degrees of sleep deprivation.

\section{Objective 2: To determine the effect that sleep deprivation has on the medical students}

The majority of the students in both year groups felt that there was not enough time to balance sleep, work and study. Possible reasons for the larger percentage in the fourth year than the fifth year include the differences in course intensity, i.e. fifth-year students are possibly more mature in their decision-making and are more comfortable with their workload and working environment due to more prolonged exposure, which might have allowed them to cope better with their academic load and management of time.

The majority of respondents felt that their confidence was negatively affected when they were sleep deprived. Despite fewer fifth-year students sharing this sentiment, nearly half of the fifth-year group felt that sleep deprivation had a negative impact on their confidence. This is in line with results reported by Parshuram et al. ${ }^{[5]}$ who found that sleep deprivation decreased the confidence levels of doctors.

The majority of fourth- and fifth-year students felt that sleep deprivation had a negative impact on their interaction with patients. The reasons they provided for their answers are in line with research that states that sleep deprivation has multiple effects, including reduced performance and vigilance, patient aversion, loss of empathy, over-optimistic risk-taking, prolonged post-call recovery and adverse events in the medical field. ${ }^{[10-12]}$

Objective 3: To establish whether the medical students feel they are adequately prepared for the long working hours and late-night shifts and the measures that could be implemented, in their opinions, to make them feel better prepared for the demands of the work environment More than half of the fourth-year students and just less than half of the fifthyear students did not feel prepared for the time requirements of the clinical phase of their training. The wide variety of open responses related mainly to the lack of available time. The students felt that the 5-year course was very demanding and full, for example: 'Changing the course to 6 years and not cramming everything in just to say we did it.' 
Objective 4: To determine the influence of clinical simulation classes on the medical students regarding the skills that they acquire, their opinions on being adequately prepared for the workload and long hours, as well as a possible reduction in errors and self-confidence when tired The recurring opinion of 'practice makes perfect' surfaced in the responses listed for both year groups. The students once again confirmed that more simulation-based training would improve their efficiency and make them more comfortable with procedures, but not prepare them better for the workload and hours of the clinical phase. One can therefore deduce, on account of the students' opinions, that the negative aspects and complications of additional simulation training would outweigh the benefits.

Objective 5: To establish whether the medical students regard late-night simulation training sessions to possibly be beneficial in preparing them for long working hours and late-night shifts

Nearly $90 \%$ of students of both year groups felt that late-night simulation classes would not be a good idea. It should be emphasised that many of the students who answered 'no', listed logistical and other minor technical details, such as student safety and lack of simulation realism, as reasons for their answers

Students do not necessarily have a negative outlook on late-night work; however, they feel that more exposure to late-night simulation during their course would not improve or prevent sleep deprivation. If the simulationbased training were to be 'realistic' and placed in a time slot that would suit the students, a different overall response to this particular question could be obtained.

Objectives 6 and 7: To describe any differences between the opinions of male v. female students and determine how many students have repeated a year in the MB ChB undergraduate medical programme at UFS, and whether there is a link to other aspects being researched

There was no statistically significant difference between the answers given by male and female students. Owing to the small number of students who failed, no association between those who failed and any other question asked in the questionnaire could be determined.

\section{Methodological errors}

During the pilot study, the suggestion was made that the interval ranges for the number of hours of sleep that students require and obtain should be changed from 1-hour to 2-hour intervals. This was altered for only 1 of the 2 questions, which made a comparison of hours required and obtained difficult.

Although an adequate response rate was recorded for this study, it could have been improved by possibly distributing the questionnaires during an academic session.

The researchers were unaware that 6 Cuban-trained students, who had different exposure to the clinical environment and simulation, were included in the study population of the fifth-year students. Although the overall effect on the data should be minimal, the impact of their responses on the results cannot be determined, as the questionnaires were anonymous.

\section{Conclusion}

The majority of respondents felt that late-night simulation would not assist them. They regarded late-night simulation as an addition to an already demanding course and therefore rejected the idea, not necessarily due to its flaws, but due to the impact it would have on their programme. The students felt that late-night simulation sessions would add extra pressure to their already time-constrained programme.

Furthermore, it can be concluded that the fourth- and fifth-year medical students at the FoHS, UFS, are familiar with the effects of sleep deprivation and are exposed to late-night shift work during their rotations. The participants were also aware of the advantages of simulation training and were positive regarding participating in this educational strategy in general.

\section{Recommendations}

This topic needs further investigation and practical testing to conclude the impact of late-night simulation classes in preparation for the shift work of medical doctors and the resultant effect on clinical performance. It would be beneficial to perform a similar study on medical interns, as they work regular shifts, experience sleep deprivation regularly and have a better understanding of the clinical environment as a whole.

Clinical testing of late-night simulation classes on a group of students or interns is planned by the research team as a step towards determining the value of such sessions, rather than relying solely on the opinions of the study population.

It could be of value to investigate students' opinions if the late-night simulation session is not be an additional session, but if it replaces one of the current simulation sessions or a clinical rotation session. Other time slots, such as from $10 \mathrm{~h} 00$ to $02 \mathrm{~h} 00$, can also be investigated.

\section{Declaration. None.}

Acknowledgements. We would like to acknowledge Dr NC Theron for his input and supervision throughout the project, Dr N Fourie for her input and diligent proofreading, Mrs C Coetzee, for proofreading and recommendations, and Ms T Mulder, medical editor, Faculty of Health Sciences, UFS, for technical and editorial preparation of the manuscript.

Author contributions. CT, T-LvZ, AJ, BK and PvdW were medical students who conceived the idea, compiled the protocol, performed the data collection and wrote the first draft of the manuscript. MGH was the study leader, who supervised the students through the project process. GJ advised with the planning of the study, performed the quantitative analysis and assisted with the write-up of the manuscript. Funding. None.

Conflicts of interest. None.

1. Health Professions Council of South Africa. Handbook on Internship Training. Pretoria: HPCSA, 2017:4-6.

2. Yasin R, Muntham D, Chirakalwasan N. Uncovering the sleep disorders among young doctors. Sleep Breath 2016;20(4):1137-1144. https://doi.org/10.1007/s11325-016-1380-6

3. De Grado J. Are you alert and oriented to person, place and time? Sleep deprivation in physicians. Grad Med Educ News 2010;15(7):22.

4. Wali SO, Qutah K, Abushanab L, Basamh R, Abushanab J, Krayem A. Effect of on-call-related sleep deprivation on physicians' mood and alertness. Ann Thorac Med 2013;8(1):22-27. https://doi.org/10.4103/1817-1737.105715

5. Parshuram CS, Dhanani S, Kirsh JA, Cox PN. Fellowship training, workload, fatigue and physical stress: A prospective observational study. Can Med Assoc J 2004;170(6):965-970. https://doi.org/10.1503/cmaj.1030442
A A prospective observational study. Can Med Assoc J 2004;170(6):965-970. https://doi.org/10.1503/cmaj.1030442
Welp A, Meier LL, Manser T. Emotional exhaustion and workload predict clinician-rated and objective patient safety. Front Psychol 2015;5:1573. https://doi.org/10.3389/fpsyg.2014.01573

7. Purim KS, Guimarães AT, Titski AC, Leite N. Sleep deprivation and drowsiness of medical residents and medical students. Rev Col Bras Cir 2016;43(6):438-444. https://doi.org/10.1590/0100-69912016006005

8. Bola S, Trollip E, Parkinson F. The state of South African internships: A national survey against HPCSA guidelines. S Afr Med J 2015;105(7):535-539. https://doi.org/10.7196/SAMJnew.7923

9. Willcock SM, Daly MG, Tennant CC, Allard BJ. Burnout and psychiatric morbidity in new medical graduates. Med J Aust 2004;181(7):357-360.

10. Sun NZ, Gan R, Snell L, Dolmans D. Use of a night float system to comply with resident duty hours restrictions: Perceptions of workplace changes and their effects on professionalism. Acad Med 2016;91(3):401-408. https:// doi.org/10.1097/ACM.0000000000000949

11. Wen J, Cheng Y, Hu X, Yuan P, Hao T, Shi Y. Workload, burnout, and medical mistakes among physicians in China: A cross-sectional study. Biosci Trends 2016;10(1):27-33. https://doi.org/10.5582/bst.2015.01175

12. Erasmus N. Slaves of the state - medical internship and community service in South Africa. S Afr Med J 2012;102(8):655-658. https://doi.org/10.7196/SAMJ.5987 
13. Murray A, Pounder R, Mather H, Black DC. Junior doctors' shifts and sleep deprivation. BMJ 2005;330(7505):1404 https://doi.org/10.1136/bmj.330.7505.1404

Hawkins F, Murphy JG, Dunn WF. 'Is my doctor impaired, or just sleep deprived?' Chest 2009;136(5):1194-1197. https://doi.org/10.1378/chest.09-1213

位ical practise: The clinical advantages. Audiol Today 2017;29(5):17-23.

16. Laack TA, Newman JS, Goyal DG, Torsher LC. A 1-week simulated internship course helps prepare medical students for transition to residency. Simul Healthc 2010;5(3):127-132. https://doi.org/10.1097/

17. Rogers GD, McConnell HW, de Rooy NJ, Ellem F, Lombard M. A randomised controlled trial of extended immersion in multi-method continuing simulation to prepare senior medical students for practice as junior doctors. BMC Med Educ 2014;14:1-10. https:// doi.org/10.1186/1472-6920-14-90

sleep deprivation. Sleep Med Rev 2003.7(4):297-310.
19. Maree K, Pietersen J. First Steps in Research. Pretoria: Van Schaik Publishers, 2012.

. Ehrlich R, Joubert G. Epidemiology: A Research Manual for South Africa. 3rd ed. Cape Town: Oxford University Press Southern Africa, 2014:133.

1. Hirshkowitz, M, Whiton K, Albert SM, et al. National Sleep Foundation's sleep time duration recommendations: Methodology and results summary. Sleep Health 2015;1(1):40-43. https://doi.org/10.1016/j.slech.2014.12.010

Accepted 27 May 2020. 